\title{
Association between smoking and body mass index among males aged 20 years and above: A study in rural Tamil Nadu, South India
}

\author{
Anil C Mathew ${ }^{1}$, Royce Kurian ${ }^{2}$, Akshaya ${\mathrm{K} \mathrm{M}^{3} \text {, Karthikeyan } \mathrm{S}^{4} \text {, Thomas V Chacko }}^{5}$
}

${ }^{1}$ Professor of Biostatistics; ${ }^{4}$ Assistant Professor; ${ }^{5}$ Professor and Head; Department of Community Medicine, PSG Institute of Medical Sciences and Research, Coimbatore. ${ }^{2}$ Trainee Biostatistician, Department of Statistics, St. Thomas College, Pala,

Kottayam. ${ }^{3}$ Assistant Professor, Department of Community Medicine, Yenpoya Medical University, Mangalore, Karnataka, India.

\begin{abstract}
A large number of epidemiological studies reported an increase in mortality due to cancer and other diseases among lean individuals. In this paper we aimed to investigate the relationship between smoking status and Body Mass Index (BMI) in men aged 20 years and above. A cross sectional study was conducted in the rural field practice area of the Department of Community Medicine, PSG Institute of Medical Science and Research, Coimbatore during June and July 2010. A total of 459 men aged 20 years and above were included in the study. Statistical analyses were done using the General Linear Model procedure of SPSS. We observed that cigarette smokers weighed (Kg) less, $p<0.01$ (age adjusted mean \pm standard error $=58.64 \pm 0.44$ ) and were leaner, $p<0.001$ [age adjusted mean BMI $\left(\mathrm{kg} / \mathrm{m}^{2}\right) \pm$ standard error $\left.=21.13 \pm 0.13\right]$ than ex/non-smokers $(61.11 \pm 0.69$ and $22.19 \pm 0.2$ respectively). Regarding the intensity of smoking and BMI, light smokers ( 1 to 20 cigarettes per day) were leaner than ex/non smokers (mean \pm standard error were $21.13 \pm 0.13,22.19 \pm 0.208$ respectively, $p<0.001)$. Regarding the duration of smoking and $\mathrm{BMI}$, a linear diminution in BMI is observed with increasing duration of cigarettes smoking compared to ex/non smokers (mean \pm standard error of BMI) for ex/non smokers $22.19 \pm 0.208,1$ to 10 years of smoking $21.56 \pm 0.221$ $(p<0.05) ; 11$ to 20 years of smoking $21.23 \pm 0.256(p<0.01) ; 21$ to 30 years of smoking $20.30 \pm 0.333(p<0.001) ; 30$ and above years of smoking $20.07 \pm 0.501(p<0.001)$. In conclusion, we found significant results confirming an association between cigarette smoking and lower BMI in men. Hence we recommended that health intervention programs to quit smoking should take into account the underlying perceived benefits of smoking with body weight.
\end{abstract}

Keywords: Smoking, BMI, Males, Underweight, Rural India.

\section{Introduction}

A large number of epidemiological studies have evidenced increased mortality particularly due to serious illnesses like cancer among lean underweight individuals compared to those of average weight.$^{1-5}$ This finding is paradoxical since several studies demonstrated greater mortality for overweight and obese persons. ${ }^{6-9}$ Several studies have assessed the relation of body weight to various behavioral characteristics including tobacco use and many of these investigations have demonstrated that lean individuals are more likely to be cigarette smokers than the overweight or obese. ${ }^{10-20}$ Consequently, the increased mortality and morbidity among underweight individuals may be due to smoking. ${ }^{18,20}$ Many epidemiological studies evaluated the relation between mortality and Body Mass Index (BMI) and the findings are varied as to whether the relation is best described as linear, $\mathrm{J}$ shaped or U shaped; and this inconsistency may be due to the confounding effects of smoking behavior and some serious illnesses. ${ }^{21,22}$ Thus, a low BMI may either be reflective of healthy life style (i.e. balanced caloric intake and physical activity energy expenditure) or be secondary to smoking and its related illness.

Tobacco use is a public health concern worldwide, as well as in India. However, patterns of tobacco use in India are

\section{Practice Points}

- Epidemiological studies reported an increase in mortality due to cancer and other diseases among lean individuals compared to those of average weight.

- Studies also confirmed that increased mortality and morbidity among underweight individuals may be due to smoking.

- Our study demonstrated that cigarette smokers weighed less and are leaner than persons who never smoked or ex-smoked confirms finding of previous investigations

- The findings of smoking and its association with low BMI highlight the potential public health impact of tobacco use and the importance of health promotion.

- Health intervention programs to quit smoking should take into account the underlying perceived benefits of smoking with regard to body weight.

Correspondence: Dr. Anil C Mathew, Professor of Biostatistics, Department of Community Medicine, PSG Institute of Medical Sciences and Research, Coimbatore-641 004, India. E-mail: anilpsgmet@gmail.com. 
quite different from those observed in other developed countries. For example, handmade cigarettes called bidis are more commonly smoked than regular cigarettes. In India, there are about 120 million smokers and among adults, almost one-third (28\%) of the population use tobacco products with $57 \%$ of males and $11 \%$ of females using some form of tobacco. If current trends continue, tobacco will account for $13 \%$ of all deaths by $2020 .^{23}$

However, research exploring the relationship between cigarette smoking and body weight has yielded conflicting results. $^{24-30}$ In some studies smoking has been associated with weight-lowering effects on men while in others such a relationship has not been found. ${ }^{12}$ Thus, this association is incompletely understood. In addition, these studies did not include information concerning, smoking history, alcohol intake and presence of chronic diseases which may confound the results.

In this study we evaluated the association between smoking and BMI among males aged 20 years and above adjusting the effect of alcohol consumption, regular physical activity and presence of chronic diseases. We compared the age adjusted mean values of height, weight, and BMI as per smoking category and also compared the age adjusted BMI for ex/nonsmokers and current smokers according to duration and intensity of smoking.

\section{Materials and Methods}

The study population consisted of males aged 20 years and above in Vedapatti, the rural field practice area of PSG Institute of Medical Sciences and Research (PSGIMSR), Coimbatore. The study got ethics clearance from Department of Clinical Research and Bioethics, PSGIMSR. As we need to interview sufficient number of smokers to investigate the association of smoking and BMI, and with an expected prevalence of smoking of $60 \%$, an allowable error of $5 \%$, the minimum number of people to be studied is 384. The baseline survey of 2008 reveals 763 households and 1050 males aged 20 years and above at Vedapatti. Hence, we decided to select fifty percentage of these households by systematic sampling (every alternate house). The survey was conducted during June and July 2010. All males aged 20 years and above from each of these selected households were interviewed which totaled to a sample size of 459 men.

Smoking data were self reported by the subjects in response to the following questions: Have you smoked at least 100 cigarettes/bidis during your entire life? Do you smoke cigarette/bidi now? On an average, how many cigarettes/bidi a day do you smoke? How long (years) has it been since you smoked cigarettes/bidi regularly? About how old were you when you first started smoking regularly? Do you feel any change in your body weight after starting smoking? How many years it has been since you have stopped smoking? Do you feel you have gained weight after stopping smoking?
Current smokers were categorized according to two smoking measures:

- Smoking intensity, defined as the usual number of cigarettes/bidi smoked daily at the time of interview (light smokers, 1-20 per day and heavy smokers, > 20 per day). ${ }^{23}$

- Smoking duration, the number of years of smoking cigarettes/bidi, derived from age of starting smoking to age at examination. ${ }^{23}$

Height and weight were measured with participants standing without shoes and heavy outer garments. ${ }^{24}$ BMI was calculated as weight divided by height squared $\left(\mathrm{kg} / \mathrm{m}^{2}\right)$. Current smokers in our study were those who have smoked more than 100 cigarettes/bidi and currently smoking. Non smokers were those who never smoked or smoked less than 100 cigarettes/bidis. ${ }^{23}$ Ex-smokers were those reporting smoking cigarettes/bidis regularly in the past but not currently. ${ }^{24}$ Alcohol consumption was coded dichotomously according to daily intake or no daily intake (Yes/No). ${ }^{26}$ Regular physical activity in our study refers to leisure-time physical exercise. Subjects were defined as physically inactive when they reported less than weekly exercise. ${ }^{31}$ Otherwise they were categorized into the group 'exercising regularly.' Selfreported illness such as allergies, cardiovascular diseases, gastrointestinal diseases, chronic liver diseases, respiratory diseases and skeletal diseases were coded dichotomously. We measured the Socio Economic Status (SES) according to Modified Prasad's SES scale based on Consumer Price Index for the month of June 2010 after rounding off to the nearest Rs.10. Accordingly, for those with per-capita income per month above Rs.3790 were classified as Class 1, Rs.1900 to Rs.3789 as Class 2, Rs.1144 to Rs.1899 as Class3, Rs 570 to Rs. 1139 as Class 4 and below Rs .70 as Class 5 .

The data were analyzed using Analysis of Covariance by the General Linear Model (GLM) procedure of SPSS (11.5).The mean and standard error values of BMI among smokers and ex/non-smokers were estimated by adjusting age as a covariate in the model and BMI, as dependent variables. Least-square means adjusted for the covariates on the model were tested for significant differences compared to ex/nonsmokers category. $p<0.05$ was considered as statistically significant. Effect of smoking on BMI was further evaluated by adding covariates; age, alcohol consumption, physical activities and chronic diseases. Similar analyses were conducted to detect the effect of intensity of smokers and the duration of smoking on BMI.

\section{Results}

The details of socio-demographic and clinical profile of the study subjects are shown in Table 1. Out of 459 persons interviewed, $328(71.5 \%)$ of the population were smokers. $323(70.5 \%)$ of them smoked at the time of examination. Forty seven respondents $(10.2 \%)$ were doing weekly physical exercises and 23 (5.1\%) reported chronic diseases. The mean $( \pm \mathrm{SD})$ of the age was 39.14 years $( \pm 12.07)$. 
Table 1: Socio-demographic and clinical profile of the respondents

\begin{tabular}{|l|c|c|c|}
\hline Variables & $\begin{array}{c}\text { Smokers } \\
\text { Number (\%) }\end{array}$ & $\begin{array}{c}\text { Non smokers } \\
\text { Number (\%) }\end{array}$ & $\begin{array}{c}\text { Total } \\
\text { Number (\%) }\end{array}$ \\
\hline $\begin{array}{l}\text { Schooling } \\
\text { No schooling }\end{array}$ & $5(3.8 \%)$ & $14(4.3 \%)$ & $19(4.1 \%)$ \\
$<=12^{\text {th }}$ standard & $112(85.5 \%)$ & $302(92.1 \%)$ & $414(90.2 \%)$ \\
Degree & $14(10.7 \%)$ & $12(3.7 \%)$ & $26(5.7 \%)$ \\
\hline Socio economic status & $45(34.4 \%)$ & $98(29.9 \%)$ & $143(31.2 \%)$ \\
Class I & $67(51.1 \%)$ & $221(67.4 \%)$ & $288(62.7 \%)$ \\
Class II & $19(14.5 \%)$ & $9(2.5 \%)$ & $28(6.1 \%)$ \\
Class III & $42(32.1 \%)$ & $37(11.3 \%)$ & $79(17.2 \%)$ \\
\hline Marital status & $89(67.9 \%)$ & $291(88.7 \%)$ & $380(82.8 \%)$ \\
Single & $127(96.9 \%)$ & $286(87.2 \%)$ & $413(90 \%)$ \\
Married & $4(3.1 \%)$ & $42(12.8 \%)$ & $46(10 \%)$ \\
\hline Alcohol Consumption & $105(80.2 \%)$ & $307(93.6 \%)$ & $412(89.8 \%)$ \\
No alcohol intake & $26(19.8 \%)$ & $21(6.4 \%)$ & $47(10.2 \%)$ \\
Daily alcohol intake & $123(93.9 \%)$ & $313(95.4 \%)$ & $436(95 \%)$ \\
\hline Physical exercise & $8(6.1 \%)$ & $15(4.6 \%)$ & $23(5 \%)$ \\
No exercise & & & \\
Do exercise & & & \\
\hline Chronic diseases & & & \\
No chronic diseases & & & \\
Have disease & & & \\
\hline
\end{tabular}

Table 2 presents the age adjusted mean values of anthropometric measurements according to current smoking status of the study population. Cigarette smokers weighed less $(p<0.01,58.64 \pm 0.44)$ and were leaner $(\mathrm{p}<0.001,21.13 \pm 0.13)$ compared to ex/non smokers $(61.11 \pm 0.69),(22.19 \pm 0.20)$ respectively.

The effect of smoking on BMI adjusting for the covariates age, alcohol consumption, regular physical activity and chronic diseases is presented in Table 3 . Adjustment for levels of physical activity, socioeconomic status, chronic diseases or alcohol intake did not alter the level of significance.

Regarding the intensity of smoking and BMI, light smokers were leaner than ex/non smokers $(21.13 \pm 0.13$,
$22.19 \pm 0.208)$. However the number of heavy smokers in our sample is too small to arrive at a conclusion on its effect on BMI.

Table 4 illustrates marginal mean values of age adjusted (age and physical activities adjusted) BMI among current smokers compared with ex/non-smokers according to duration of smoking in years. Regarding the duration of smoking and BMI, a linear diminution in BMI is observed with increasing duration of cigarettes smoking compared to ex/non smokers.

We further evaluated the relationship between BMI and smoking status according to below average (20-40 years old) and above average age group (above 40 years old) of the study population. Cigarette smokers were leaner

Table 2: Estimated mean values of age adjusted Body Mass Index (BMI) \& standard error (S.E.) by smoking category

\begin{tabular}{|l|c|c|c|r|c|}
\hline \multirow{2}{*}{$\begin{array}{l}\text { Anthropometric } \\
\text { measurements }\end{array}$} & \multicolumn{2}{|c|}{ Current Smoker } & \multicolumn{2}{c|}{ Ex/Non- Smokers } & \multirow{2}{*}{$\boldsymbol{p}$-value } \\
\cline { 2 - 5 } & Mean & S.E. & Mean & S.E. & \\
\hline Height $(\mathrm{cm})$ & 166.36 & 0.28 & 165.81 & 0.44 & 0.307 \\
\hline Weight $(\mathrm{kg})$ & 58.64 & 0.44 & 61.11 & 0.695 & $<0.01$ \\
\hline Body Mass Index $\left(\mathrm{kg} / \mathrm{m}^{2}\right)$ & 21.13 & 0.13 & 22.19 & 0.20 & $<0.001$ \\
\hline
\end{tabular}

Table 3: Effect of smoking on BMI with adjusted covariates

\begin{tabular}{|l|c|c|}
\hline Adjusted covariates & $\begin{array}{c}\text { Regression Coefficient } \\
\mathbf{( 9 5 \% C I )}\end{array}$ & $\boldsymbol{p}$-value \\
\hline Adjusted for age & -1.067 & $<0.001$ \\
\hline Adjusted for age and alcohol consumption & $-1.602,-0.624)$ & $<.966$ \\
\hline Adjusted for age, alcohol consumption and regular physical activity & $(-1.502,-0.525)$ & $<0.001$ \\
\hline $\begin{array}{l}\text { Adjusted for age, alcohol consumption, regular physical activity and chronic } \\
\text { diseases }\end{array}$ & -0.983 & $<0.001$ \\
\hline
\end{tabular}

South East Asia Journal of Public Health 2014;4(1):53-58 
Table 4: Effect of duration of smoking on BMI [age adjusted (age and physical activity adjusted)]

\begin{tabular}{|c|c|c|c|c|}
\hline \multirow[t]{2}{*}{ Duration } & \multirow[t]{2}{*}{ Number } & \multicolumn{2}{|c|}{ BMI } & \multirow[t]{2}{*}{$p$-value } \\
\hline & & Mean & S.E. & \\
\hline Ex/ Non- Smokers & 136 & $22.29(22.30)$ & $0.208(0.210)$ & Reference \\
\hline $\begin{array}{l}\text { Current Smokers } \\
\text { ( } 1 \text { to } 10 \text { years) }\end{array}$ & 143 & $21.56(21.55)$ & $0.221(0.222)$ & $<0.05(<0.05)$ \\
\hline $\begin{array}{l}\text { Current Smokers } \\
\text { (11 to } 20 \text { years) }\end{array}$ & 88 & $21.23(21.23)$ & $0.256(0.256)$ & $<0.01(<0.01)$ \\
\hline $\begin{array}{l}\text { Current Smokers } \\
\text { (21 to } 30 \text { years) }\end{array}$ & 61 & $20.30(20.28)$ & $0.333(0.335)$ & $<0.001(<0.001)$ \\
\hline $\begin{array}{l}\text { Current Smokers } \\
(30+\text { years })\end{array}$ & 31 & $20.07(20.07)$ & $0.501(0.501)$ & $<0.001(<0.001)$ \\
\hline
\end{tabular}

(mean $\mathrm{BMI} \pm \mathrm{SE}$ ) than ex/non-smokers in both below average and above average age groups $(21.42 \pm 0.18$, $21.76 \pm 0.24 ; 20.81 \pm 0.18,23.37 \pm 0.37)$. However, the association between smoking and BMI is significant $(p<0.001)$ only after the age of 40 years.

\section{Discussion}

The high prevalence of tobacco use in the study population and its association with low BMI raises important questions about the potential public health impact of tobacco use. The findings that cigarette smokers weighed less and are leaner than persons who never smoked or ex-smoked confirms finding of previous investigations. ${ }^{10-20}$ In this population former smokers were very few in number. These findings are complemented by the observation that compared to nonsmokers, smokers gained less weight.

The association between smoking and BMI were not explained by the differences in physical activities, SES, chronic diseases or alcohol intake. Many previous investigations on the relation between smoking intensity and body weight reported an increased average weight and obesity levels among the most intense smokers. ${ }_{11,16,19}^{10}$

In our study, light smokers were found to have significantly lower BMI than ex-smokers and non-smokers and supports earlier findings. ${ }^{27}$ However, the number of heavy smokers in our area was too small to compare BMI with ex/non-smokers. It is possible that heavy smoking forms part of a cluster of substance abuse behaviors (including over-eating and alcohol consumption), where-as in light smokers the association with a smaller BMI could be related to the known metabolic effects of nicotine. A nearly linear diminution in BMI associated with increasing duration of cigarette smoking was demonstrated in this study population, having taken independently age as well as age and physical activity into consideration. Although these findings are based upon cross-sectional data, they are suggestive of a cumulative effect, and offer a coherent and biologically plausible representation of the effect of smoking on BMI. It is also interesting to note that the association between smoking and BMI is significant after the age of 40 years which explains that the older age groups would include substantial number of long-term smokers.
Several mechanisms might account for these findings with respect to smoking and BMI. Increased gastro intestinal motility in smokers due to effects of nicotine, which could result in appetite suppression and less absorption of food calories, has been observed by some investigators. $^{23}$ Smoking is also related to decreased meal size ${ }^{27}$ and some smokers may use smoking as a marker for meal termination or simply substitute cigarettes for meals together. ${ }^{28}$ In addition, tobacco use among the economically disadvantaged is known to reduce the resources available to purchase food, clothing, health care and education, all factors that contribute to poor nutritional status besides its direct physiologic effect, which will lead to lower the BMI. An increased number of illness and hospitalizations among current smokers could, on theory, account for some increase in caloric expenditure or leanness among smokers. However, in our study, even though we adjusted the presence of these diseases, there was a strong association between smoking and lower BMI.

Awareness of the interrelation between smoking and BMI is necessary to both clinical and public health practitioners attempting to modify either of the two characteristics in individuals. This is especially true for smoking cessation efforts. In many epidemiological studies, tobacco use strongly confounds the relation between absolute or relative body weight and cancer as well as other diseases or causes of death. Evidence for such confounding is available from studies which assessed smoker's status and demonstrated that leanness was a risk factor among cigarette smokers only. ${ }^{1,2}$ Our findings suggest that increased mortality observed among lean individuals reported in previous studies may have been due to smoking rather than leanness. ${ }^{23}$

\section{Limitations}

Our study has several limitations; First, this is a cross sectional study. Thus the causal relation cannot be determined between smoking and BMI. Second, the present study does not allow adequate evaluation of the hypothesis that individuals who become smokers are leaner to begin with. However, among the current smokers, $252(77.81 \%)$ felt that they had weight loss after starting smoking. Third, we have not evaluated the effect of smoking on BMI adjusting the effect of stress as well as caloric intake which may confound the results. Fourth, the questions to smoker's data and 
physical activity have not been formally validated in the study population.

\section{Conclusion}

In conclusion, we found significant results confirming an association between cigarette smoking and lower BMI in men. This association was not diminished by adjustment of physical activity, alcohol intake and presence of chronic diseases. It is worthwhile to prospectively investigate this phenomenon in other parts of the population and hence need more such studies.

\section{References}

1. Lew EA, Garfinkel L. Variations in mortality by weight among 750,000 men and women. $J$ Chronic Dis 1979;32:563-76.

2. Sorlie P, Gordon T, Kannel WB. Body build and mortality: the Framingham study. JAMA 1980;243:1828-31.

3. Jarrett RJ, Shipley MJ, Rose G. Weight and mortality in the Whitehall study. BMJ 1982;285:535-7.

4. Rhoads GG, Kagan R. The relation of coronary artery disease, stroke and mortality to weight in youth and middle age. Lancet 1983;1:492-5.

5. Expert Committee. Physical status: the use and interpretation of anthropometry. Technical Report Series no. 854. Geneva: WHO, 1995.

6. McCay CM, Sperling G, Barnes LL. Growth, ageing, chronic diseases, and life span in rats. Arch Biochen J 1943;2:469-79.

7. Tannenbaum A. Effects of varying caloric intake upon tumor incidence and tumor growth. Ann NY Acad Sci 1947;49:5-17.

8. Weindruch R, Walford RL. Dietary restriction in mice beginning at 1 year of age: effect on life span and spontaneous cancer incidence. Science 1982;215:1415-8.

9. Ross MH, Lustbader ED, Bras G. Body weight, dietary practices and tumor susceptibility in the rat. JNCI 1983;71:1041-6.

10. Dawber TR, Kannel WB, Revotskie N, Stokes J, Kagan A, Gordon T. Some factors associated with the development of coronary heart disease. Am J Public health 1959;49:1349-56.

11. Ashford JR, Brown S, Duffield DP, et al. The relation between smoking habits and physique, respiratory symptoms, ventilatory function, and radiological pneumoconiosis amongst coal workers at three Scottish collieries. Br J Prev Soc Med 1961;15:106-16.

12. Higgins MW, Kjelaberg M. Characteristics of smokers and nonsmokers in Tecumseh,
Michigan. Am J Epidemiol 1967;86:60-70.

13. Jenkins CD, Rosenman RH, Zyzanski SJ. Cigarette smoking: its relationship to coronary heart disease and related risk factors in the Western Collaborative Group Study. Circulation 1968;38:1140-55.

14. Bjelke E. Variation in height and weight in the Norwegian population. $\mathrm{Br} J$ Pre Soc Med 1971;25:192-202.

15. Kesteloot H, Vuylsteke M, Houte OV. Distribution and consequences of smoking habits in a cross-sectional epidemiological survey. $J$ Chronic Dis 1976;29:301-10.

16. Khosla T, Lowe CR. Obesity and smoking habits. $B M J 1971 ; 4: 10-3$.

17. Goldbourt U, Medalie JH. Characteristics of smokers, non-smokers and ex-smokers among 10,000 adult males in Israel. Am J Epidemiol 1977;105:75- 86.

18. Jacobs DR Jr, Gottenborg S. Smoking and weight: the Minnesota Lipid Research Clinic. Am J Public Health 1981;71:391-6.

19. Nemery B, Moavero NE, Brasseur L, Stanescu DC. Smoking, lung function and body weight. $\mathrm{Br}$ Med J 1983;286:249-51.

20. Fehily AM, Phillips KM, Yarnell WG. Diet, smoking, social class, and body mass index in the Caerphilly Heart Disease Study. Am J Clin Nutr 1984;40:827-33.

21. Manso JE, Stampfer MJ, Hennekens CH, et al. Body weight and longevity; a reassessment. JAMA 1987;267:353-8.

22. Willett WC, Dietz WH, Colditz GA. Guidelines for healthy weight. $N$ Engl J Med 1999;341:42734.

23. Global Epidemic. The Toll of Tobacco. Campaign for tobacco free kids. International Edition. Available from: http:// www.tobaccofreecenter.org (accessed June 2014)

24. Tavani A, Negri E, La Veccia C. Determinants of body mass index; a study from northern Italy. Inj J Obes Relat Metab Disord 1994;18:497-502.

25. Boyle CA, Dobson AJ, Egger G, Magnus P. Can the increasing weight of Australians be explained by the decreasing prevalence of cigarette smoking? Int $J$ Obes Relat Metab Discord 1994;18:55-60.

26. Klesges RC, Klesges L M. The relationship between body mass and cigarette smoking using a biochemical index of smoking exposure. Int $J$ Obes Relat Metab Disord 1993; 17:585-91. 
27. Fitzgeraid AP. Jarrett R J. Body weight and coronary heart disease mortality; an analysis in relation to age smoking habit: 15 years follow-up data from the Whitehall Study. Inj J Obes Relat Metab Disord 1992;16:119-23.

28. Shah M, Hannan PJ, Jeffery R W. Secular trend in body mass index in the adult population of three communities from the upper mid-western part of the U.S.A.; the Minnesota Heart Health Program. Int J Obes 1991;15:499-503.
29. Wolk A, Rossner S. Effects of smoking and physical activity on body weight; developments in Sweden between 1980 and 1989. J Intern Med 1995;237:287-91.

30. Istvan J. Murray R, Voelker H. The relationship between patterns of alcohol consumption and body weight: Lung Health Study Research Group. Int J Epidemiol 1995;24:543-6.

31. Albanes D, Jones Y, Micozzi MS, Mattson ME Association between Smoking and Body Weight In the Us population: Analysis off NHANES II. Am J Public Health 1987 April; 77(4):439-44. 